\section{UNIFICATION OF BOTANICAL SCIENCE}

\author{
By Prof. C. W. WARDLAW \\ University of Manchester
}

\begin{abstract}
"Botany is the science which treats of plants." - Oxford English Dictionary.

"Every speculation about a single phenomenon wrenched from the continuity of life, is playing indeot a thankless part in the present condition of the natural sciences."-SCHLEIDEN, 1838.

"An unflinching determination to take the whole evidence into account is the only method of preservation against the fluctuating extremes of fashionable opinion."-A. N. WHITEHEAD, 1926.

"An upward outlook is in itself a practical applica. tion of any evolutionary view."-F. O. BOwER, 1935.
\end{abstract}

A

NY biological phenomenon can be considered from several different points of view, each of which may lead to the formulation of particular and distinctive concepts. In some instances concepts relating to different aspects may overlap : in other instances they may belong fundamentally to different categories. Now, it is a fact that botanical science has developed erratically and spasmodically ; botanists have embraced strange and irreconcilable philosophies; they have welcomed innovations and canalized them into fashions or moulded them into new branches of the science. Moreover, the results forthcoming from the several distinctive phases have not invariably been studied with due regard to their mutual relationships, nor have they necessarily been envisaged as contributing directly to a generalized scheme. The piecemeal character of the scientific advance and the diversity of its branches of underlying philosophy have increased notably during the last fifty years; for it has been a period of great, if non-co-ordinated, activity along many seemingly divergent lines of inquiry. Cogent reasons, therefore, exist for the view that the time is at hand when an effort should be made to achieve some closer integration of the science as a whole.

As a result of the growing volume of research on almost every branch of botany and the concurrence of certain contemporary lines of investigation, there is a reasonable hope that certain gaps that have hitherto hindered synthesis may in due course be bridged and that this may lead towards a real unification of outlook. To some, no doubt, this may appear as unjustifiable optimism. The question may indeed be asked why this topic is considered to merit special attention at the present time. It may be argued that botanical science does not in fact lack unity, that it has been adequately unified at various times in the past, or that complete unification is difficult or even impossible. Moreover the nature of the unification envisaged itself requires elucidation: What kind of unification and for what purpose ? I have in mind both the conceptual and methodological aspects : the former is concerned with general questions, that is, possessing significance for the plant kingdom as a whole ; the latter considers the results of a particular discipline in relation to those of all other relevant disciplines, instead of such results being treated in comparative isolation. It is this latter aspect of unification that $I$ consider of particular importance at the present time.

It seems evident that failure to achieve some progressive method of integration in the near future will be attended by such an accumulation of non-co- ordinated data as to dismay contemporary botanists and bewilder their successors. There is no novelty in this view, but emphatic reiteration seems timely. In the long view, teaching and research are insepar. able; failure to collate the main results of contemporary and past work will certainly militate not only against reasonable advance but also impede the proper teaching of the subject.

In the realm of biological science, where a sense of ever-increasing complexity appears to be the chief reward of the most profound investigations, the less complicated structure and mechanism of plant life, as compared with animal life, might be expected to afford a more direct approach to the fundamental problems of organic Nature. Hence an unbiased observer might take it for granted that botanists would automatically take the lead in the formulation of new concepts and the enunciation of broad generalizations. Reference to some recent works on general biology can scarcely be considered to support this view; indeed, a certain neglect of botanical work is apparent by adherents of other branches of biology. It may be that botanists are to blame ; for while collectively their science abounds with new and impressive discoveries, it may be argued that these have not been presented in such a way as to be readily accessible to the general reader. The justification for seeking to co-ordinate the various branches should lie not only in its desirability on philosophic grounds but also in its results. Past prophecy as to the future direction of scientific achievement has not enjoyed such a success as to encourage present attempts, but it seems evident that a period of great synthetic development is on its way. This potential development, however, will only become actual if a synthesis, dynamic and progressive, of all new knowledge is steadily maintained in some reasonably accessible form. Thus a contributory channel of specialized research would be seen not only in relation to neighbouring channels but also to the course of the main stream.

\section{Botany and the Botanists}

"Botany is the science which treats of plants" $(O x$ ford English Dictionary), and in an extended definition is usually understood to include a consideration of their growth, development and reproduction, the functions of their organs, their origin, systematic affinities, geographical distribution and relation to their environment. Some years ago Prof. W. Stiles indicated that in his view there could be no such thing as a general botanist: that an investigator may take a sympathetic interest in other branches of the science and realize the bearing of such work on his own, but that the latter, in these days of specialization, must necessarily lie in one particular field. Clearly in such a statement there is ground both for agreement and dissent. In so far as an investigator fails to realize the relation of his work to the science as a whole, so may he fail to appreciate the actual and potential development of the subject in his time.

What, then, do we hope to make of "the science which treats of plants"? What, in particular, is to be the relationship of the specialized branches, for example, plant biochemistry or genetics, to the parent science?

The last five decades have witnessed a great expansion of botanical research in the course of which new aspects, each requiring detailed investigation by means of special technique, have become distinct, specialized and almost separate branches of 
biological science. To-day, a botanist tends to be labelled systematist, cytologist, geneticist, ecologist, mycologist, morphologist, palæontologist, physiologist or biochemist, the underlying assumption being that he is that and little else. A further unfortunate consequence of specialization lies in the fact that common ground for discussion becomes more and more difficult to find, and in extreme.cases may even lead to the view that it does not, for practical purposes, exist. Although an official cleavage between botanical morphology and physiology was avoided at the British Association meeting of 1894 in Oxford, nevertheless an adequate sense of mutual aid in the common pursuit is still lacking. The morphologist will tell you, with some over-emphasis but not without justification, that when he looks into text-books of physiology in search of information bearing on his own work, he finds that such books can tell him little that he specially wants to know ; and the modern physiologist, though not habitually addicted to helping himself by making the fullest use of morphological observations, rather tends to view the professed morphologist as a relic of a former phase of botanical development and as a less adaptable and less inventive scientific man who is still plodding along in an overworked field ; moreover, he, too, may com. plain that morphological literature fails to provide the information he specially requires. So, too, uneasy relationships exist between other and newer branches of the science. Each new aspect that arouses enthusiasm is soon attended by a profuse outpouring of specialized literature, and this, no doubt, must be accepted as being in the nature of things. But several important consequences should not be overlooked. These include: (1) vast accumulations of reading matter which are such that a worker in any single branch has to read constantly to keep up to date; and (2) an increased specialization of outlook, which, if left uncorrected, will make for a progressive disintegration of the science as a whole.

Now, no one would desire that specialization in the various branches of botany should cease. Such close investigation of particular phenomena is of the very nature of the scientific method. Indeed, the more facts these branches can produce, the better for biological science as a whole, provided they are made readily available to readers working in other branches. The crux of the problem, then, is this: How is the contemporary botanist, conscious of the need for achieving a full and coherent account of the plant and its life, to make the best use of the several contributory branches without wishing to deny to them the fullest freedom to pursue their own aims? For two things are certain : (1) no single human being can now hope to read in detail the literature of the several special branches; (2) no particular branch will relinquish its aims or limit its scope for the sake of the mother-subject. Thus it is not a question of re-uniting the several separate branches, or of making any one the hand-maiden of another, but of being able to synthesize or integrate the facts of these branches in the interests of the central aims of botany.

Before attempting to take the matter further, it may be advantageous to consider briefly some selected aspects of the development of botanical science.

\section{Early Developments}

It is almost certain that the early systematists, having arranged in orderly fashion the species of plants known to them, must have been conscious of having imparted coherence where none had previously existed. Here it is appropriate to refer to the works of John Ray (1628-1705), of whom Sachs has written that he "not only knew how to adopt all that was good and true in the works of his predecessors, and to eriticize and complete them from his own observations, but could also joyfully acknowledge the services of others and combine their results and his own into a harmonious whole". The tribute is deserved, for though Ray's "Historia Plantarum" consists essentially of a series of descriptions of all plants then known, the work is prefaced by an account of morphology, anatomy and physiology as then understood. Later, too, Linnæus, having achieved the completion of his system, must have been conscious of having created a new and desirable unity. Along entirely different lines the German botanist, Caspar Wolff, discussed general questions such as the fundamental nature of the shoot system, and concluded, as stated in his "Teoria Generationis", 1759, that he saw nothing in the plant but leaves and stem. Later, inspired no doubt by Wolff's generalization, Goethe formulated his theory of metamorphosis in which all the various and diverse appendages of the shoot in higher plants were regarded as being the metamorphosed products of a single fundamental organ, the 'ideal' leaf. Here, indeed, the nature philosopher had conferred a unity on the objects of his study, but as Schiller pointed out to him, the abstract conceptions which he employed belonged to the realm of ideas rather than of facts.

The scholastic tradition which prevailed during the first half of the nineteenth century died hard, and botanical science made indifferent headway until Schleiden trenchantly preached a new gospel-that the highroad to new discovery lay in the study of development. It remained for his disciple Wilhelm Hofmeister to show what could thus be done. To view his work in proper perspective it is necessary to realize how very little was then known of the Cryptogams and indeed of the life-history of higher plants. The reproduction and embryology of Bryophytes and Pteridophytes constituted practically an unexplored field, while precise data relating to the development of the embryo-sac, fertilization and embryology in the higher plants were still being collected-all this rather less than a hundred years ago. The contemporary botanical world may well have been astonished when it first read the curious catalogue title of Hofmeister's paper : "Comparative Researches on the Germination, Development and Fruit Formation of the Higher Cryptogams (Mosses, Ferns, Equisetaceæ, Rhizocarpaceæ and Lycopodiaceæ) and the Seed-formation of the Conifers" (1851). It must have appeared as if the wrong things, mosses and gymnosperms, had somehow been run together for comparative treatment. But this was no fallible production, nor was the strange association of data an indication of faulty judgment, for the young German botanist was telling the world that mosses, liverworts, lycopods, equiseta, ferns, gymnosperms and phanerogams all shared a common life-cycle, characterized by the same critical events and developmental phases, and by a recurrent alternation of generations. Here, on a substantial basis of observation, was a synthesis which conveyed a sense of unity hitherto unknown. Later, in 1896, following on the discovery of chromosome behaviour, Strasburger was in a position to announce the further important generalization of the relation between the chromosomecycle and the somatic-cycle. 


\section{Hofmeister's General Morphology}

These and other examples which could be quoted afford evidence of the way in which new data and the generalizations which could be based on them not only widened the scope of botanical science but also conferred on it a new sense of coherence. These instances, however, do not convey any adequate idea of the methodological unification which I consider to be desirable. For such a discussion the starting-point lies in the works of Hofmeister, for he was not merely concerned with preparing descriptive accounts of changes in form during development, but he also asked himself such questions as : How does the observed form come to be ? To what processes of growth can the observed structural developments be related? What internal and external factors determine specific structural organization ? The substance of such investigations he described as general morphology. Not only did he consider the problems of form from the physiological aspect, but he also actually carried out physiological investigations. In short, it may be claimed for him that he achieved a view of the whole field of botanical research which, within the limits of contemporary knowledge, could not well have been bettered; with suitable modifications it is one to which we might well aspire to-day.

In introducing his new point of view to a botanical world largely given over to the speculative writing inseparable from the then prevailing idealistic morphology, Hofmeister employed little general argument. Instead of this he set about the task of replacing lold conceptions by new ones'based on personal investigations. A clue to his general attitude is surely given in the title of his book: "General Morphology of Growing Things" (Gewächse). As Von Goebel has said : "in this book form-relations are presented as conditions of growth. This growth is investigated". Lastly, to round off our impression of the all-round 'compleat' botanist, it may be men. tioned that Hofmeister interested himself in the question of variability in plants and, while demanding further studies of the influence of external factors on the conformation of organisms, he attached himself to the Darwinian theory of descent.

\section{The Phyletic Period}

As a result of Hofmeister's admirably objective inquiries and of his critical search for relationships between physiological activity and the assumption of specific form or pattern, it might have been thought that botanical science had at length been established on a broad and sure foundation, one in which morphology and physiology were seen to be inseparable aspects of the same theme. But in what has been called the phyletic period-that which followed the publication of Darwin's theory of descent-the details of plant structure, together with such facts as could be culled from the fossil record, were regarded chiefly as providing materials for comparative studies and for the construction of phylogenetic systems. The sweeping success of Darwin's views must surely have indicated to professed phylogenists that whatever comparative investigations they carried out were bound to 'fit in' somewhere, to contribute in some measure to the wonderful edifice of evolutionary theory. The facts of development and the characteristic features of the adult were thus accepted by them as purely morphological concepts, while physiological and causal aspects, though not entirely neglected, received at best little more than passing attention. But as Prof. W. H. Lang pointed out in an important review of the situation in 1915, the problems of general, that is, causal morphology, would remain even if the phyletic history were before us in full $\boldsymbol{A}$ bad feature of the phyletic period was the tendency of morphologists and anatomists to resort to facile pseudo-physiological arguments regarding the function and adaptive value of structures and organs. Meanwhile physiological research was going on its own way, out of sympathy, or out of touch, with the historic aspirations and interests of morphology.

\section{Organization and Phylogeny}

Each of the major phases in the development of botanical science has been characterized by a central idea. Thus in the Linnæan period the beau ideal was to know and classify as many species as possible and to add to that number by new collections from all the ends of the earth. In the Darwinian period and after, the problem of descent, which included the construction of phylogenetic systems, was the chief aim, use being made of the natural classifications which had been evolved during the preceding descriptive phase. Since the beginning of the present century, the mechanisms underlying physiological and hereditary processes have constituted leading themes. For contemporary workers in both botany and zoology the processes involved in progressive organization during development are providing problems of great importance and interest.

Now it is evident that organization could be studied as a subject per se, without reference to origins. But since all contemporary organisms have come from ancestors possessing greater or less family antiquity, and since the fossil record informs us that notable changes in structure have taken place down through the ages, it is clear that, whatever may be the findings from our studies of organization in contemporary organisms, such findings must also in some way be related or referable to the historic or evolutionary aspect. This, of course, is implicit in the once firmly held view that the ontogeny of any organism is a recapitulation of its phylogeny. It is apposite to note here that the modern study of organization differs from phyletic studies in that it is essentially dynamic in outlook.

The comprehensive viewpoint, therefore, will require that the results of contemporary investigations of plant organization be also considered in relation to the fossil record of past biological events. If an adequate understanding of the factors underlying the organization of living plants can be achieved, a fuller interpretation of the events indicated by the fossil record may become possible, though it can never be absolute. Whether the concepts issuing from contemporary studies of organization will support the criteria of comparison which have been used in the construction of phylogenies or will indicate that they lack validity is evidently a matter of the greatest importance and interest.

\section{Entelechy and Holism}

Since Driesch considered mechanistic conceptions of life to be inadequate he introduced the idea of a controlling or ordering principle-an entelechywhich was independent of physico-chemical laws though these were operative in living systems.

In his important work on "Holism and Evolution", General Smuts, too, considers that the explanation of living organisms cannot be purely mechanical and that mechanistic concepts have their place, and 
justification only within the wider framework of the integrated unity of the organism. According to him, holism-defined as the "fundamental factor operative towards the creation of wholes in the universe"-is a vera causa, that is, a causal factor with a real existence ; in the process of evolution there is a definite and fundamental tendency towards the creation of wholes, the results becoming more marked at progressively higher levels of organic development. Thus, if we take a plant or animal as a type of a whole, "we notice the fundamental holistic characters as a unity of parts which is so close and intense as to be more than the sum of its parts; which not only gives a particular conformation or structure to the parts, but so relates and determines them in their synthesis that their functions are altered; the synthesis affects and determines the parts, so that they function towards the whole; and the whole and the parts, therefore, reciprocally influence and determine each other, and appear more or less to merge their individual characters : the whole is in the parts and the parts are in the whole, and this synthesis of whole and parts is reflected in the holistic character of the functions of the parts as well as of the whole".

Whether one agrees or disagrees with the philosophical or biological implications of holism, a valuable service has been rendered to biology by the author's insistence on the essential wholeness of organisms. In the pursuit of researches into particular aspects this integrated unity should not be forgotten.

\section{Contemporary Aspects of Integration}

A survey of certain current biochemical, physiological, genetical and morphological investigations suggests that opportunities for achieving a useful integration of data derived from these several branches do in fact exist. Admittedly the number of instances which may be cited is not great; nevertheless they constitute a beginning which may in due course be notably extended.

The marked increase of interest on the part of biochemists in isolating and determining the chemical composition and physical properties of a number of physiologically active substances is likely to prove of great importance in promoting certain aspects of contemporary botanical research. In some instances these substances, which have been comprehensively described as activators, show remarkable specificity in their action on living tissues. A number of these substances have now been synthesized; an obvious development in biochemistry is to synthesize yet others. A considerable number of physiologically active organic substances of known composition, not so far known to occur in Nature, have also been produced. Physiologists, meanwhile, have been attempting to ascertain the metabolic origin and functional relationships of naturally occurring activators. This exacting branch of plant physiology is one in which substantial progress may be anticipated in due course.

The relation of these developments to the work of the morphologist may now be considered. Morphologists are concerned with the external and internal configuration of plants and regard the facts of embryology, the development of new organs at apical growing points and the attendant differentiation of tissues as integral parts of their work. Hitherto they have laboured under a serious handicap in that they have had very few working hypotheses to account for the mechanism underlying the differentiation of new organs or of new tiasues. The observed develop. ments have been regarded as characteristic manifestations of the specific hereditary substance, or in some such generalized fashion, but hypotheses relating to the operation and interaction of individual factors have been inadequate or lacking. Hence the purely descriptive nature of much morphological work and the indefinite nature of many of the conclusions based on it. But to-day a fascinating prospect of new possibilities lies before us. For example, it is known that certain substances which the biochemist can isolate or synthesize are more or lesis directly involved in those all-important initial differentiations of organs and tissues, or in the subsequent growth to the adult condition. Those substances, which apparently exercise a specific morphogenetic effect, have been described by Dr. J. Needham as morphogenetic hormones. Whether or not, in the complex of factors operative in the moulding of an organ, a single substance can properly be referred to as 'morphogenetic' cannot be discussed in detail here; the important fact is that specific structural developments follow on the application of certain substances to plant and animal tissues, provided the latter are in a suitable physiological condition.

Physiologists have not only been exploring the many aspects of what may be described as general cellular physiology, they have also been investigating those difficult problems which are concerned with the movement of substances throughout the plant body. It is now known, for example, that auxins, produced at the apical growing point of the shoot, that is, the region of active formation of protoplasm, become distributed throughout the plant. Important developments ensue, for example, the inhibition of buds, promotion of root development and the progressive enlargement of tissues. Now these several develop. ments provide the materials which the morphologist is competent to investigate and of which he wishes to render an account either in terms of comparative morphology or in explanation of how the organization or configuration observed in the adult comes to be. In short, the biochemical, physiological and morphological aspects are seen to be inextricably linked, and conjoint work is essential to any reasonably adequate account of the processes involved.

Any relationship that can be established between the hereditary constitution of an. organism and the possession of those metabolites which are significant in the development of its specific morphology will represent an important advance in botanical science. Here the interests of the geneticist, the physiologist, the biochemist and morphologist become confluent. So far the instances which permit of a co-ordination of data are few in number. They are, however, of great interest, not least because they indicate the possibility of such work being extended.

In an investigation of tall and dwarf strains of maize it has been ascertained $(a)$ that the difference between tall and dwarf races is referable to the action of a single pair of genes, (b) that the initial production of auxin, an important factor in the growth-expansion of tissues, is approximately equal at the growing points in the two races, and (c) that the characteristic dwarfness in one race is due to the destruction of a large part of this auxin by an oxidase not present in the tall race. Here we have a genetical observation relating to an important difference in morphological configuration, which in turn can be assigned to analysable differences in metabolio activity. When precise, co-ordinated data of this kind become cumulative, as they probably will in time, the 
information already gathered by morphologists and systematists may well acquire new significance and provide a new viewpoint from which to consider the central and continuous problem of evolution. Admittedly this is looking far ahead, but the goal is much to be desired.

The relation between genes and developmental processes has only recently begun to receive the attention which the subject so evidently deserves. The lack of co-ordinated development in related branches has no doubt been a contributing factor. At present very little is known about the actual physiological expression of a gene-how and where it exerts its influence : it may affect only one step in the process of development or a chain of processes ; or it may be involved systemically in every aspect of development. Indeed, it is held to be improbable that any single formula will be found to unify all observations on the connexion between the influence of a gene and its results.

Biological materials in which some well-marked character is known from genetical analysis to be related to a single pair of genes seem likely to prove of great use in attempts to relate genes with developmental processes. In certain annual and biennial forms of Hyoscyamus niger it has been shown that if grafts of annual-flowering plants are applied to biennial stocks in their first year, flower-bud development is induced in the latter ; and if the vegetative biennial scions are grafted on to annual shoots they are induced to become flowering shoots. The evidence suggests that a substance (or substances), directly or indirectly operative in flower-bud development, has passed from the tissues of the annual to those of the biennial. Now this factor, which is associated in the hereditary constitution with a single pair of genes, is productive of changes which are of profound interest to both the physiologist and the morphologist. Other instances illustrating the same community of interest relate to such characters as the shape and size of leaves, total growth, branching, difference in chlorophyll content, flower size and shape and sterility. In each, the indications are that gene-dependent diffusible substances are involved; in each the materials are such as to call for detailed physiological investigations and are of the kind on which classical systematic and morphological studies have been based.

Here, perhaps, it is appropriate to utter a word of caution. The subject-matter has been treated in such a way as to illustrate how a plurality of distinct branches of botanical science can be focused, to their mutual advantage, on the same phenomenon. But it would be a mistake to assume that the actual opera. tional relationships involved are simple. Behind every change and development lies all the complexity inevitably associated with the multifarious operations of a metabolic system. Hence, while there is a need for simplification so that main issues and essential relationships are not obscured, the innate complexity of the processes involved should not be underestimated. Experience suggests that it is unlikely that any so-called specific morphogenetic substance is as direct in its moulding activity as the words would appear to imply. It is safer to assume that every morphological development is the result of the interaction of many factors.

To summarize briefly. The guiding lines are these : the hereditary constitution of a species, itself a small fragment of the evolutionary picture, is conceived as being subdivisible into genes; these are involved in all developmental processes; they find expression in the action of chemical substances, which in conjunction with temporal, spatial and physical factors are directly or indirectly operative in morphogenetic processes and culminate in the production of the distinctive organization of the adult.

\section{Tissue Culture}

An all-pervading consideration in biology is the physiological mechanism relating to the assumption of form, that is, to the origin of the ontogenetic growth pattern and its development to the adult status. How are we to approach this very difficult problem, and how are we to test such hypotheses as may be constructed? What, for example, are the factors leading to the institution of an apical meristem ? How is it maintained in its active formative capacity ? To what can we attribute the orderly development of leaf and bud primordia? What factors determine their bilateral and radial symmetry respectively and the characteristic shapes into which they are moulded during development? And the overriding 'wholeness' of the organism, what of that ? These are questions on which we scarcely know how to make a beginning, for the problems are of a manifold complexity. We note that they involve the origination of cells (cytogenesis) and of organs: (organogenesis) - in fact, all that is connoted by the word morphogenesis; but they also involve a great. deal more.

One possible line of approach, on which a beginning if no more has been made, is by means of tissue culture. The advances made during the last thirty years in mycological and bacterial cultural methods have played an important part, and media of precise composition can be prepared on which the tissue of certain plants can be maintained in a state of growth without differentiation for an indefinite period. Here then are the means by which it may be possible to determine experimentally, on materials of known genetic constitution maintained under controlled conditions, the direct or indirect action of many factors considered to be operative in morphogenesis. Whether this hope is vain or whether it will, in fact, be realized, remains to be seen.

\section{Conclusion}

In this essay it has been quite impossible to refer to all aspects of the unification of botanical science. Studies of plant distribution, for example, which are of interest not only to the systematist, geneticist and ecologist but also to the morphologist and physiologist, have of necessity been omitted from the discussion. So, too, with taxonomy and other important branches. I have attempted to illustrate a point of view, not to cover the field.

To bring out particular points, I have referred to both conceptual and methodological aspects of unification. There are important instances where the two may be closely related. For example, the phylogenist makes use of certain morphological criteria of comparison. The validity of these criteria depends, among other things, on the accuracy of our knowledge of morphogenesis and this, on a further analysis, is seen in practice to require the conjoint work of the biochemist, physiologist and morphologist.

From the multiple-aspect-study of organization during development we not only derive some impression, however inadequate, of the organism as a whole; 
we are brought face-to-face with the undeniable wholeness of the organism. A case has been made out for the view that the over-emphasis of any single aspect, while the whole is not kept in proper perspective, will almost certainly lead to the fabrication of unstable theoretical superstructures, destined to crumble because they have not been based on the fundamental reality of organic wholeness. This is a matter which concerns all botanists, though each, according to his capacity, must perform his detailed work in a particular field. But whatever that field may be, he will at one time or another be concerned with some aspect of the distinctive growth-pattern of the organism which he is investigating; this, it need scarcely be said, is of paramount interest to the morphologist at large. An interesting contrast that has been drawn between the 'substance-minded' and the 'relation-minded' man is relevant to the present discussion. "The substance-minded type of thinking," says A. H. Hersch, 1941, "is unquestionably the older, both in the individual and the race. It has all the tenacity of original sin. In morphology it has given us representative particles, preformation, the transmission of a cquired characters, and such morphochemical hybrids as bristle-producing, facet-forming substances, and so on. The morphologist, when substance-minded, thinks of the developmental pattern in terms of the visible structural characteristics from stage to stage. In short, he thinks in terms of a series of pictures. But when relation-minded, the morphologist recognizes that the pattern at any moment is the expression of the events which produce it, and attempts to gain a knowledge of the durations and rates, and relative durations and relative rates of the component processes in the developmental nexus. Consequently, instead of thinking in terms of a series of pictures, the relation-minded morphologist tends to think in terms of the non-picturable. If the problem of the developmental pattern is similar to the problems of the more exact sciences, then no doubt in time a system of equations will be developed to facilitate our thinking about it".

There is the modern outlook on one aspect of morphology. While it is evident that certain comparative studies and all fossil studies will continue to conform to the older pattern, the new point of view suggests great possibilities for further exploration. The feasibility of pursuing these investigations to a successful conclusion will in large measure be determined by the existence of the tools to do the job. Some of these are already at hand. Here I have in mind certain major biological works recently published or reissued, for example, D'Arcy Thompson's "Growth and Form" (2nd edn.), Needham's "Biochemistry and Morphogenesis" and Child's "Problems of Pattern and Development". Each tends to emphasize a particular aspect, but taken together they afford both the morphologist and physiologist a working knowledge of the several biochemical, physical, physiological, temporal and spatial factors which, at one or another stage of development, may be operative in moulding the distinctive form of the organism.

The publication of a major work, such as any one of those mentioned above, or of a first-class text-book, is an event of rather occasional occurrence, and depends on particular individuals twho possess the experience, capacity and urge to attempt a synthesis. Now, the point of view conveyed in Hofmeister's general morphology, with appropriate modernization and thereafter subject to progressive integrated development, would appear to represent a desirable central aim in botanical science with which few would disagree. With this as a focal point, it is cogent to inquire how we are to make the best use of the data of each of the special branches, having in mind the volume of such literature, the present tendency of individual workers towards intensive research in a restricted field, the fact that this may involve disability to broader vision, and the finite mental capacity of human beings. It is undeniable that the proper comprehension of the subject as a whole is suffering from the inevitable and progressive increase in specialization. How do we propose to deal with this situation ?

I claim no originality in raising this general question and offer no solution at this stage. It is evident that underlying the numerous symposia, conferences, joint-meetings and so on, that from time to time have been convened, the same or a not dissimilar point of view has obtained; but a more definite policy needs to be framed, continuously pursued and kept to the fore in our biological deliberations. The question of how this is to be done is for botanists collectively to decide. The time for doing so is at hand if a great opportunity is not to pass unheeded.

In conclusion, I wish to express my gratitude to colleagues for suggestions and much helpful criticism ; but for the opinions expressed responsibility lies wholly with myself.

\section{SCIENCE AND INDUSTRY*}

\section{By J. G. BENNETT}

\section{Director, British Coal Utilisation Research Association}

CURREN'T discussions as to the part which science 1 should play in industry are often vitiated by misconceptions as to what science and the scientific activity really are. Science is not the mere use of scientific apparatus to ascertain facts, nor the use of scientific jargon to describe them. Again, we should not use the term science to include the testing of materials and the control of technical processes as practised in modern industry. All this should be regarded as part of engineering and production technique, which only incidentally requires particular kinds of apparatus and men with a particular training. Science is not primarily a matter of technique but a specific activity of the human mind.

The scientiflc activity is as definite in its character as, for example, the artistic activity or the organizing activity, and in its highest form is as rare as either.

The basic scientific processes are observation, experiment and hypothesis formation. Hypothesis formation consists in applying to observations of natural phenomena an act of creative thought, which discovers in them a meaning which they previously did not possess. This new meaning then suggests new lines of thought and new lines of observation and experiment. The essential feature is that the new hypothesis is more than an orderly presentation of the data. It is a new view of the working of Nature, which is important as much because it is new as because it is valid.

The validity of a hypothesis is a purely relative conception, for we can never know the last word about Nature, and the whole progress of science con-

* Substance of an address at the inaugural session of the NorthFastern Section of the Institute of Fuel, Newcastle-upon-Tyne, delivered on October 18 . 